\title{
Pro- and anti-inflammatory Cytokines in Coronavirus Disease 2019
}

\author{
Batool Hassan Al-Ghurabi ${ }^{1}$, Luma Ghaeb Al-Saadi ${ }^{2}$, Sahar Hashem Al-Hindawi ${ }^{3}$ \\ ${ }^{1}$ Prof., Department of Basic Science, College of Dentistry, University of Baghdad, Iraq, ${ }^{2}$ Assit. Prof., Biology \\ Department, College of Science, Al-Mustansiriyah University, Iraq, ${ }^{3}$ Assit. Prof., Department of Basic Science, \\ College of Dentistry, University of Baghdad, Iraq
}

\begin{abstract}
It has long been believed that cytokines have an important function in immunopathology during viral infection. Coronavirus disease 2019 (Covid-19) is a contagious viral disease caused by severe acute respiratory syndrome coronavirus 2 . Covid-19 can be fatal because of an overactive immune response and release of cytokines. This review focuses on the role of cytokines in COVID-19.
\end{abstract}

Keywords: COVID-19, cytokines, Immune response.

\section{Introduction}

Coronavirus disease 2019: Coronavirus disease 2019 is the infectious disease caused by (SARS-CoV-2) severe acute respiratory syndrome coronavirus 2 . First identified in December 2019 in Wuhan, and has since spread all over the world, resulting in the ongoing 201920 coronavirus pandemic ${ }^{[1]}$. Main symptoms include fever, dry cough and fatigue. It may be accompanied by runny nose, sore throat, vomiting and diarrhea. Most patients have mild symptoms, while a few develop into viral pneumonia and multi-organ failure. The incubation period of virusis generally 5 days however may range 2 to 14 days. The disease can spread from person to person through small droplets produced by coughing,sneezing, or talking. These droplets land on objects and surfaces being infectious over long distances ${ }^{[2]}$. Low protective immune response causes the virus to spread and destroy infected tissues, especially in organs that have high angiotensin-converting enzyme 2 expressions, such as intestine and kidney. The damaged cells induce innate

\footnotetext{
Corresponding Author:

Batool Hassan Al-Ghurabi

Prof., Department of Basic Science, College of

Dentistry, University of Baghdad, Iraq

e-mail: batoolamms@yahoo.com
}

inflammation in the lungs that is largely mediated by pro-inflammatory macrophages and granulocytes. Lung inflammation is the main cause of life-threatening respiratory disorders at the severe stage $\mathrm{e}^{[3]}$.

Role of Cytokine in COVID-19: Cytokines are inflammatory immunological proteins that act as molecular messengers between cells, which fight infections and ward off cancers. The overproduction of specific inflammatory cytokines is a hallmark of viral infection $^{[4]}$. It has been suggested that the pathogenesis of COVID-19 is mediated by disproportionate immune responses and the ability of the virus to circumvent innate immunity ${ }^{[5]}$. When COVI-19 infects the upper and lower respiratory tract it can cause mild or highly acute respiratory syndrome with consequent release of proinflammatory cytokines ${ }^{2}$. Chen and colleagues reported that COVID-19 might mainly act on lymphocytes, especially $\mathrm{T}$ lymphocytes, and induce a cytokine storm in the body, which is characterized by increased plasma concentrations of cytokines ${ }^{[6]}$. Mehta, et al recently stated there is accumulating evidence suggests that a subgroup of patients with severe COVID-19 might have cytokine storm syndrome. The authors suggest that patients with severe stage must be screened for hyperinflammation and subgroups of patients identified for whom immunosuppression therapy could improve mortality ${ }^{[7]}$. However, in most moribund patients, 2019$\mathrm{nCoV}$ infection is associated with a cytokine storm ${ }^{[8]}$. 
In those who survive intensive care, these aberrant and excessive immune responses lead to lung damage and fibrosis, causing functional disability and reduced quality of life ${ }^{[9,10]}$.

Proinflammatory Cytokines: Cytokine storm is a systemic inflammatory response that can be triggered by a variety of factors such as infections. ShimabukuroVornhagenet al., pointed out that during the cytokine storm, three important cytokines in the IL- 1 family are involved IL-1 $\beta$, IL-18, and IL-33 ${ }^{[11]}$. Recent study declared that COVID-19 stimulate pro-inflammatory cytokines productionsuch as IL- $1 \beta$ and IL- 6 via the toll like receptors that causes the release of active mature $\mathrm{IL}-1 \beta$ which is a mediator of lung inflammation, fever and fibrosis ${ }^{[12]}$.

It is well known that TNFs are key inflammatory factors that trigger a cytokine storm. They are attractive targets for controlling the cytokine storm. Similarly Qin and colleagues showed that most patients with COVID-19 had high erserum levels of TNF- $\alpha$ along with IL-1 and IL-6, elevation levels of these cytokines have also been found in patients with severe COVID-19 as compared to the non-severe ones ${ }^{[5]}$.On the other hand Chinese medical researchers have found that the increased expression of interleukin-2 receptor and IL-6 in serum is expected to predict the severity of the 2019$\mathrm{nCoV}$ pneumonia and the prognosis of patients ${ }^{[13]}$. Likewise higher plasma levels of other inflammatory cytokines (IL-7, IL-8, IL-9, IL-10, MCP-1, and IFNgamma etc.) were observed in patients with COVID-19 (2). IL-17play a role in pathogenesis of COVID-19 infection and blocking it could help those patients who have high level of $\mathbf{~ I L - 1 7 ^ { [ 1 4 ] }}$. Additionally, in severe cases, a reduction of $\mathrm{CD} 4+$ and $\mathrm{CD} 8+\mathrm{T}$ cells and a decrease of regulatory $\mathrm{T}$ cells has been found, likely due to high expression of proinflammatory cytokines in COVID-19 patients $^{[5]}$.

Anti-inflammatory Cytokines: Anti-inflammatory cytokines, such as IL-1Ra, IL-37 or IL-38, can provide relief in both systemic inflammation and fever that occur after infection.Conti et al., demonstrate that the suppression of IL-1 $\beta$ by IL-37 in inflammatory state induced by COVID-19can have a new therapeutic effect previously unknown. As well IL-38 is a potential therapeutic cytokine which inhibits inflammation in viral infections including that caused by COVID-19, providing a new relevant strategy ${ }^{[13]}$. Dissimilar SARS patients, patients withCOVID-19 also have elevated levels of Th2 cell secreted cytokines (such as IL-4 and IL-10), which inhibit the inflammatory response ${ }^{[3]}$. However, infection with 2019-nCoV appears to be initially associated with an increased Th2 response, which might reflect a physiological reaction to curb overt inflammatory responses ${ }^{[2]}$.

\section{Conclusion}

In conclusion both T-Th1 and Th2 cytokines underline the role of the immune processes in the pathogenesis of COVID-19.

Conflict of Interest: The authors and planners have revealed no possible conflicts of interest, financial or else.

Ethical Clearance: From Ethical Committee, College of Dentistry, University of Baghdad.

\section{References}

1. Hui DS, Azhar E, Madani TA, et al. The continuing 2019-nCoV epidemic threat of novel coronaviruses to global health-The latest 2019 novel coronavirus outbreak in Wuhan, China. Int J Infect Dis. 2020; 91: 264-66.

2. Huang C, Wang Y, Li X, et al. Clinical features of patients infected with 2019 novel coronavirus in Wuhan, China. Lancet. 2020; 395: 497-506.

3. Xu Z, Shi L, Wang Y, et al. Pathological findings of COVID-19 associated with acute respiratory distress syndrome. The Lancet Respiratory Medicine. 2020.

4. Wong CK, Lam CWK, Wu AKL, et al. Plasma inflammatory cytokines and chemokines in severe acute respiratory syndrome Clin Exp Immunol. 2004; 136(1) 95-103.

5. Qin $\mathrm{C}$, Zhou $\mathrm{L}, \mathrm{Hu} \mathrm{Z}$, et al. Dysregulation of immune response in patients with COVID-19 in Wuhan. China Clin Infect Dis. 2020.

6. Chen N, Zhou M, Dong X, et al. Epidemiological and clinical characteristics of 99 cases of 2019 novel coronavirus pneumonia in Wuhan, China: a descriptive study. Lancet. 2020. 7. Mehta P, McAuley DF, Brown M, et al. On behalf of the HLH Across Speciality Collaboration, UK. COVID-19: consider cytokine storm syndromes and immunosuppression. Lancet. 2020.

8. Hui DSC, Zumla A. Severe acute respiratory syndrome: historical, epidemiologic, and clinical 
features. Infect Dis Clin North Am 2019; 33: 86989.

9. Batawi S, Tarazan N, Al-Raddadi R, et al. Quality of life reported by survivors after hospitalization for Middle East respiratory syndrome (MERS). Health Qual Life Outcomes 2019; 17: 101.

10. Ngai JC, Ko FW, Ng SS, To KW, Tong M, Hui DS. The long-term impact of severe acute respiratory syndrome on pulmonary function, exercise capacity and health status. Respirology 2010; 15: 543-50.

11. Shimabukuro-Vornhagen A, Gödel P, Subklewe M, et al. Cytokine release syndrome. J Immunotherapy Cancer. 2018; 6: 56.
12. Conti $\mathrm{P}$, Ronconi $\mathrm{G}$, and Caraffa $\mathrm{A}$, et al. Induction of pro-inflammatory cytokines (IL-1 and IL6) and lung inflammation by COVID-19: antiinflammatory strategies $\mathrm{J}$ Biol RegulHomeost Agents 2020; 34(2):1.

13. Chen L, Liu HG, Liu W, et al. Analysis of clinical features of 29 patients with 2019 novel coronavirus pneumonia Chin J Tuberc Respir Dis. 2020; 43.

14. Zumla A, Hui DS, Azhar EI, et al. Reducing mortality from 2019-nCoV: host-directed therapies should be an option. The Lancet. 2020. 